\title{
Lo legible irónico: retracción y supervivencia de la garantía científica en Cataratas de Hernán Vanoli
}

\author{
NICOLÁS GARCÍA Universidad Nacional del Sur, Argentina \\ ORCID 0000-0001-6158-3631 \\ gnicolas.88@gmail.com
}

\section{Resumen}

La distopía no deja de expandirse en el panorama literario argentino actual y es un problema para la crítica distinguir las invariantes genéricas de aquello que se presenta de por sí alterado. La descripción de un mundo ligeramente futuro, tomado por grandes trusts biotecnológicos y sus efectos en la uniformización de la intersubjetividad, en una novela reciente como Cataratas de Hernán Vanoli (2015), es inescindible — como se intentará probar- de un uso deliberado de teorías sociales. ¿Qué función cumplen estas en una literatura que si bien se percibe como heredera de la ciencia ficción ha perdido cientificidad? A pesar de una incuestionable heterodoxia, la legibilidad genérica, y por ende, su legalidad, nunca estuvo más a salvo — diremos_ - entre sus recreadores.

Palabras clave: Vanoli / Cataratas / ciencia ficción / sátira / distopía
The ironical readerly: retraction and survival of the scientific guarantee in Hernán Vanoli's

\section{Cataratas}

Abstract

Dystopia has not ceased to spread in the current Argentine literary scene and it is a problem for critics to distinguish generic invariants from what appears to be altered in itself. The description of a slightly future world, captured by large biotechnological trusts and their effects on the standardization of intersubjectivity, in a recent novel such as Cataratas by Hernán Vanoli (2015), is indivisible - as we will try to prove - from a deliberate use of social theories. What role do these fulfill in a literature that, although perceived as the heir to science fiction, has lost scientificity? Despite an unquestionable heterodoxy, the generic legibility, and therefore its legality, was never safer than among its recreators.

Key words: Vanoli / Cataratas/ science fiction / satire / dystopia

Recibido: 4/3/2020. Aceptado: 6/7/2020

Para citar este artículo: García, N. (2020). Lo legible irónico: retracción y supervivencia de la garantía científica en Cataratas de Hernán Vanoli. El taco en la brea, 12 (junio-noviembre). Santa Fe, Argentina: UNL. eooo4 DOI: 10.14409/tb.vii12.9681 


\section{Introducción}

La permeabilidad de las fronteras que caracteriza a la ficción científica se hace evidente en la manera en que absorbe características de otros géneros. Tal como lo advierte Link, la ciencia ficción presenta una dimensión doble (6). Las operaciones estéticas efectuadas por obras inscriptas en el sistema de una literatura de entretenimiento producida serialmente, acorde a cánones impuestos por la industria cultural, debería poder distinguirse de otras, cuya finalidad difiere de la "pasatista», al mestizarse con géneros de la tradición clásica. Estos son, puntualmente, la utopía, la literatura fantástica y la sátira. El cruce de la ciencia ficción con elementos genéticos de otra procedencia dista de ser una práctica de la contemporaneidad. Al mismo tiempo, si hay algo que diferenciaría históricamente a la ciencia ficción' de la literatura fantástica —en esto coinciden los críticos- sería su cientificidad, es decir, cierto rigor lógico en el tratamiento de sus temas y en la construcción de hipótesis teóricas plausibles que motiven la anticipación. «Ciencia ficción es la literatura de la imaginación disciplinada» es la definición tomada de Judith Merrill que elige Pablo Capanna (1966:6) como más pertinente para definir la especificidad del género. Es fácil tildar de anacrónica una definición que supone el rigor conceptual de la ciencia como método de observación social a los fines de la extrapolación lógica, ${ }^{2}$ aspecto que —en principio, se cree— habría colapsado en las nuevas elaboraciones de esta literatura. La disolución de la identidad genérica en estos relatos se daría como consecuencia del debilitamiento de los saberes científico-antropológicos que oficiaban de garantía del potencial de conocimiento y del verosímil realista de la ciencia ficción clásica, plantea De Rosso. La naturalización del elemento extraño que oficiaba de novum amenazante en el período clásico del género, sumado al desplazamiento de la ciencia y la clase de misterios explorados por aquella, por la indagación de los enigmas en torno a las redes de poder características del capitalismo tardío, serían rasgos comunes al «desdén cognitivo» que experimentarían tanto la New Wave como el Cyberpunk y sus secuelas contemporáneas (De Rosso). Sostenemos, disintiendo con este autor, que, de cumplirse esto, no repercutiría sobre la totalidad de la nueva narrativa de anticipación. La realidad es que el impulso epistemológico está más vivo que nunca en algunas de las reelaboraciones actuales más representativas de un género cuya conjeturalidad no se ha apartado todavía lo suficiente del ethos evaluativo originario. La racionalidad científica, creemos, sigue siendo el horizonte epistémico hegemónico del extrañamiento cognitivo que practican algunos de los autores más destacados de la nueva ficción especulativa. ${ }^{3}$ El elemento decisivo para comprender las particularidades genéricas que las distopías de Hernán Vanoli comparten con la ciencia ficción clásica es el relativo al lugar todavía preeminente que se le otorga a la cognición científica, en su variante «blanda», ${ }^{4}$ y su injerencia en la tendencia desenmascaradora de la sátira. La presencia aún pregnante de estos dos elementos centrales del sistema del género afectan de un modo novedoso la conjeturalidad, atributo esencial del juego narrativo que propone esta clase de literatura (Eco). Entendemos que las distopías posgenéricas de Vanoli —y en especial, Cataratas, que aquí analizaremos - representan un intento de desvío de la episteme de la ficción de anticipación, con resultados imprevistos. ${ }^{5}$ Su fracaso — de ocurrir-consistiría en no lograr quebrar la lógica cognoscitiva que, amparada en un ethos satírico, es, aún hoy, su ley última.

\section{Legibilidad, ironía, garantía científica}

Si bien ha sido leída como subgénero de lo fantástico, la ciencia ficción se aparta considerablemente de los principios estructurales de esa clase de relatos y se acerca paradójicamente más 
a un tipo de construcción realista. Si en algo se distingue de otros géneros del fantástico, esto se debe a la clase especial de plausibilidad que introduce. Como señala Butor en su artículo pionero sobre la lógica genérica de la ciencia ficción, el verosímil de esta narrativa no coincide con el efecto de lo maravilloso, para el cual la creencia en lo sobrenatural es una condición de posibilidad del pacto de lectura. Todorov, años más tarde, describiría esta convivencia aparentemente contradictoria, en el marco de una episteme racionalista, entre lo fantástico y lo posible bajo la fórmula de lo maravilloso científico (41). No estaríamos, en suma, ya en presencia del shock perceptivo por ruptura con el universo de sentido que plantea el efecto de fantástico. Aquello que acontece en los relatos de ficción científica no es plenamente del orden de lo cotidiano y, no obstante, no puede considerárselo como opuesto o en contradicción con los principios que regulan la vida social. La introducción de elementos futuristas ligados a la tecnología, en instancias de desarrollo no alcanzadas aún, no implica la separación definitiva de la realidad por parte de esas obras, o solo en la medida en que esto permita "prolongar» lo real en un plano de lo posible. Esto explica la definición de la ciencia ficción como género conjetural, con un matiz particular: por trabajar con hipótesis acerca de la realidad futura cuya garantía es tan firme, debido a que el discurso científico que opera como sostén de su imaginario cuenta con una amplia legitimidad, habilita la impresión de lo real. Su efecto de realidad es producto de que el conjunto de doctrinas y creencias que constituyen la ciencia moderna operen como el marco de percepción fundamental que garantiza la plausibilidad de la realidad evocada; ${ }^{6}$ plausibilidad, proporcional a la solidez de los elementos científicos que el autor introduce. Si estos estuvieran ausentes, la ciencia ficción devendría una forma muerta, un cliché o un cuento de hadas trasplantado en el futuro, sostiene Butor en referencia a la CF del período campbelliano. La ciencia puede variar en sus campos de referencia y en sus técnicas evocadas, pero es siempre la que constituye la especificidad del género, de acuerdo a esta perspectiva dominante. ${ }^{7}$ A este carácter hegemónico del metalenguaje científico en la composición textual, que tendría como función encuadrar el componente fantástico del género en un tipo de realismo, Butor lo denomina, de manera precursora, "garantía científica» (224).

Diremos también que no ha sido el único en señalar que la especificidad de esta literatura estaría dada por un tipo de exploración del campo de lo posible solo tal como se lo permite entrever la ciencia. Narrativa de extrañamiento, la ciencia ficción se concentra en un futuro cognoscitivamente plausible, afirma Darko Suvin, tal vez el teórico más destacado del género. La presencia de una cognición científica es la condición necesaria del tratamiento del novum, novedad que altera la norma de realidad y pone en duda las leyes del mundo empírico. A diferencia de los géneros literarios sobrenaturales, la realidad que es objeto de desplazamiento en la ciencia ficción, por lo tanto, solo es interpretable en el marco del horizonte cognoscitivo. También en cuanto reacción contra el abuso de la ciencia capitalista represiva, la variante distópica se apoya por entero en un paradigma científico. El carácter predictivo del relato admonitorio y la condición de posibilidad de esos mundos futuros estarían asegurados a partir de la extrapolación de tendencias sociales dominantes del mundo actual. El recurso de la anticipación es el correlato de la búsqueda de extracción de un patrón de la suma de las experiencias sociales, que haga comprensible el presente histórico. Literatura de anticipación, antiutopía, roman cientifique, coincidirían en el examen de los efectos políticos y antropológicos del conocimiento y los avances de la razón técnica, mediante la hiperbolización de los rasgos sobresalientes de la sociedad 
tecnocrática. La huida del contexto colectivo del autor representa un truco epistemológico cuyo objeto es conformar un punto de vista totalizante desde el cual captar las relaciones objetivas, que propicie la desalienación de la experiencia (Suvin:118). Es la sociología, por ende, el código cultural primario proveedor de los semas nucleares y del ethos cuestionador del género. Este es el sentido que debe otorgársele al argumento central de Suvin que afirma que la ciencia es su «horizonte limitador» (98).

En lo relativo a la técnica literaria, coinciden los críticos en destacar que el valor cognoscitivo de la ciencia ficción radica en su referencia analógica al presente, basada en los procedimientos de la hipérbole y la inversión satirizantes. La extrapolación por analogía, procedimiento decisivo tanto de la utopía como de su forma invertida, implica necesariamente una valoración de aquello que se percibe como futurible y por ende esencial a un tiempo histórico. Esa valoración no es otra cosa que el contrafactual, que en la forma negativa de la utopía se caracteriza por una clase de representación de la realidad signada por su deformación irónica (Eco). La ironía —componente pragmático de la sátira (Hutcheon) - es el tropo esencial de la función desenmascaradora del presente que persigue el relato de anticipación. Si el género funciona aún como «instrumento de investigación» (Butor:226) es gracias a la permanencia de la todavía dominante función satírica. En lo que aquí nos ocupa —el análisis de la continuidad del impulso cognoscitivo en la ciencia ficción contemporánea- basta con indagar en las teorizaciones más significativas de la literatura distópica para comprobar cómo una y otra vez se repite el razonamiento que asocia, como parte de una entidad indivisible, distopía y crítica social. ${ }^{8}$ La relación originaria entre sátira y utopía está probada desde los estudios pioneros de Adorno, Frye y Rabkin, entre otros. Frye afirma que la distopía se vuelve una reacción satírica al género utópico, a partir de mediados del siglo XIX, cuando se constata que el avance técnico conduce a la uniformización de la vida en sociedad (327). Tanto la apelación a la variante utópica del género como a la distópica implican necesariamente una axiología, ya sea que mediante esta se sugiera la aprobación o la desaprobación del mundo que se describe. Toda literatura de anticipación, entiende Rabkin, en la propuesta misma de un mundo alternativo al nuestro con el fin de cuestionar sus males inherentes, es idealista, es decir, «aspira a algo mejor» (Link:31). ${ }^{9}$ A lo que debe agregarse que el «idealismo» de la sátira variará de signo de acuerdo a si es evocado bajo la forma textual de la utopía o de su reverso. En la antiutopía el rol de los elementos satíricos estaría al servicio no de confirmar la deseabilidad del proyecto utópico, sino, en contraste con aquel, para reducir al absurdo las tendencias sociales existentes que sirven como base del deseo utópico en una fase totalitaria o semitotalitaria.

En resumen, la cognición científica solo puede darse en el marco de una cierta legalidad estética que se autovalide por medio de la apelación a un discurso último y autorizante. Dado que la economización coercitiva del sentido sería la condición general de todo texto clásico, como opina Barthes, creemos posible emparentar el tipo de reducción valorativa que la sátira ejerce sobre sus modelos con el régimen de enunciación de la ficción científica. La naturaleza del sentido, en tanto fuerza que intenta someter a otros lenguajes y, por ende, a otros sentidos, alcanzaría su máxima expresión en la plenitud del texto legible (Barthes:129). Para esto, los elementos de aquel deben hallar su justificación en un código cuya naturaleza sistematizadora consista en la acción de recubrir todo lo notable del mundo. La diferencia sustancial del texto clásico y el texto moderno radicaría en el modo en que este último fuerza el muro de la enunciación mediante su multivalencia constitutiva —aspecto ausente en el primero—. La imposibilidad de identificar el origen último 
de los enunciados en el texto multivalente sería la consecuencia de la negación de toda referencia fundante, debido a la destrucción de una voz última capaz de darle su unidad y su coherencia. Por esta razón, la multivalencia siempre rechaza la ironía o su ironía nunca es segura. La parodia -y la sátira, cabría agregar-, en cambio, es siempre una palabra "clásica», indica Barthes (36). Al estar dirigida por un enunciador que sitúa su imaginario a distancia del lenguaje de los otros, le permite a este constituirse en sujeto del discurso. En síntesis, creemos posible equiparar la legibilidad de la escritura clásica que describe Barthes con la estabilidad tonal del régimen de enunciación de la ciencia ficción distópica, como consecuencia del lugar predominante que el género (también en su variante posmoderna) le da a la validación científica y la ironía, en tanto principales estrategias retóricas conjuntas. La ironía es la forma de enunciación congruente con la tendencia conceptualizadora de la ficción de anticipación, caracterizada por ejercer la valoración desde la seguridad de un código de referencia legítimo que no es otro que el científico. Pero esta puede ser segura o puede no serlo, de acuerdo a qué lugar ocupe el enunciador en relación con la "garantía científica». Hay razones suficientes para remitir la literatura de Vanoli a ambas morales.

\section{La nueva garantía científica: Vanoli o la imposible desujeción}

Michel Butor observa que la última promoción de autores de ciencia ficción —ya en los años 50- se enfrentaba a la paradoja de seguir pretendiendo que la función develadora del destino de la sociedad rigiera la moral del género, cuando sus fundamentos habían perdido la solidez científica necesaria que le proporcionaban la apariencia de distinción con la literatura fantástica, otorgándole precisión a las imágenes de ese mundo alternativo. El requisito de una cultura científica superior a la media sería indispensable para el verosímil técnico del género, tanto como el conocimiento de la realidad presente, comparable a aquel que supone una novela realista (Butor:234). En el contexto hispanoamericano, una parte de la crítica ha abordado la presencia de la ficción de anticipación en la literatura reciente a partir de la idea del debilitamiento hasta el grado de la casi inexistencia del componente científico constitutivo del género. La pérdida que Cohen juzga definitiva del «poder de alarma» y el «vigor de conocimiento e inquisición» de esta clase de relatos, según una parte importante de la crítica actual, se habría vuelto la tendencia dominante de la novela futurista. Las ficciones científicas vernáculas del último tiempo presentarían características comunes tanto en su dificultad para «constituir saber a partir del relato» (De Rosso:313) como para establecerse dentro de los límites definidos del género. Este diagnóstico supone - ya que no ha sido aún explicitado— que, de cumplirse estas condiciones, la ciencia ficción argentina se encaminaría hacia su estadio paródico. Cabe recordar que la cualidad distintiva de la ficción anticipatoria con relación a otras subespecies de la literatura fantástica —en esto coinciden los críticos principales - es la plausibilidad de sus hipótesis, derivadas del juego especulativo propio del método científico (Butor; Todorov; Suvin; Eco; Freedman; Capanna, 2007). Su función predictiva es el correlato de una «actitud metódica» (Capanna, 2007), producto de que el conjunto de doctrinas y creencias que constituyen la ciencia moderna operen como el marco de percepción fundamental que garantiza la plausibilidad de la realidad evocada por esta.

Sin embargo, cabe señalar que otros enfoques, en lugar de aludir a una suerte de crisis terminal de la cognición científica del género en sus manifestaciones actuales, asumen un cambio en la dirección de la preocupación por la relación entre ciencia y cultura. Esta, en el presente, estaría orientada a la exploración política de la formación de imaginarios sociales y utópicos, 
la construcción de identidades comunitarias, la otredad y las formas de vida en el capitalismo tardío, entre sus aspectos principales (Kurlat Ares, 2017). ${ }^{10}$ La conjunción de metaliterariedad y actitud crítica, incluso banalizante, de los contenidos científicos específicos de la CF, con la consecuente desverosimilización del género, ejercida desde el paradigma desenmascarador de las ciencias sociales, sería predominante en las últimas décadas en hispanoamérica (Cano:258). Esta observación es fundamental para comprender la evolución de la "garantía científica» que aún opera como sostén del deseo de realidad implícito en una zona importante de la ciencia ficción contemporánea. El saber de las lógicas sociales que imperan en el funcionamiento de lo real suple el desinterés o la merma de protagonismo de la cultura científica en el verosímil técnico de la distopía posgenérica. En esta, el espíritu científico se sublima como sociocrítica elevada a código primario de la ficción. La validación de la nueva ficción futurista sigue teniendo como base la ciencia, pero con una novedad, esta última deja de estar implícita solo en la estilización crítica de los contenidos sociales y pasa a ocupar el lugar del código narrativo.

Si bien es cierto que en Cataratas (2015) el discurso sabio de la sociología cataliza toda la acción, integrado al código de la distopía, se desborda en una contaminación aberrante con la ficción paranoica en sus variantes más banales e integradas a la lógica de la industria cultural. Utopía del conocimiento social y utopía política, de raigambre marxista ambas, convergen —según el modelo analógico del novum de la CF- transformadas en residuos históricos, pero además, genéricos, en una clara inversión irónica. La presencia de la lógica del simulacro, tematizada en Cataratas y, progresivamente, también, inscripta en su forma, indicaría la insistencia de una intención cognoscitiva que busca zafar de la malla de simulaciones, pero las estructuras narrativas mediadoras que persiguen un anhelo epistemológico nunca logran plenamente colmar. La narración omnisciente y el registro científico social-satírico que, en principio, encarnarían instancias de separación de esa inmanencia de la simulación, promoviendo una distancia crítica, a la larga se igualan con esta. El pastiche desautoriza ese estrato moral superior y sume el punto de vista en el mismo principio uniformizante que rige las relaciones reificadas de la sociedad del espectáculo tratadas. El ethos evaluativo de la ironía persiste a lo largo de la novela, pero dentro de una estructura que es paradójica y parece dejarla privada de garantías. La paranoia, la sobreabundancia de índices conspirativos que componen el régimen normal de percepción de los cientistas sociales que protagonizan Cataratas, no es otra cosa que el resultado de la hiperbolización del componente cognoscitivo «degenerado» de la ficción científica.

El primer aspecto a considerar en lo relativo a la degradación de la garantía es temático. Se hace visible en el pesimismo epistemológico tematizado en la perspectiva del cinismo ilustrado de los cientistas sociales en cuanto a los alcances de una sociología crítica de la sociabilidad del capitalismo tardío. La burocratización del cientismo social, diagnóstico reiterado implícito en el descreimiento del becario tipo de la novela, se revela como signo de una época en la que la degradación de lo real a su simulacro se propaga por todas las esferas. La ciencia, en su variante sociocrítica, es parte fundamental de la tendencia totalizadora que adopta la simulación, como efecto de su inactualidad y su pérdida de eficacia explicativa. «La fenomenología ya no sirve para nada, y a nadie le interesa resucitarla, pensó. Debería dejar de refritar ponencias» (Vanoli:17). Varios son los signos prodigados en la novela que tematizan el descrédito de la ciencia, empezando por la descomposición lúdica y las transformaciones continuas del significado de las siglas de CONICET, que atestiguan la relación irónica de Osatinsky y Ramus con su medio social y su trabajo («Consejo Residual 
de Fermentaciones Oníricas y Técnicas», o «Consejo Nacional de Investigaciones Fraudulentas y Tóxicas» - 21 y 32-). A la obsolescencia de los contenidos de la teoría le corresponde un medio de propagación virtual que es acorde a su carácter meramente instrumental. El investigador social promedio aspira, a lo sumo, a desplegar ingeniosamente frases en la red social de la «elite» progresista, Mao, en una muestra clara de cómo el impulso ilustrado de la teoría en el futuro se reificaría en un tipo de sociabilidad narcisista en la que prima la seducción virtual. Está claro que la exposición de la transformación del saber crítico de la sociedad en bibliografía legítima y apta solo para la validación académica es uno de los ejes de la sátira de la novela, y en ese sentido, sigue valiéndose de una perspectiva sociológica a distancia de su objeto, que oficia como sostén. El saber de la degradación de la teoría crítica y de la paradoja de su subsunción en la racionalidad de los fines imperante en el medio social es el equivalente a la garantía científica clásica del género.

La tesis de doctorado de Gustavo Ramus reflexionaba sobre la ciudad, sobre las figuraciones de lo urbano en el nuevo cine argentino y brasileño. Su hipótesis principal era que el proceso de urbanización de ambos países determinaba de forma compleja a las estéticas; se centraba en Buenos Aires, Córdoba y Rosario para la Argentina, y en Río de Janeiro, San Pablo y Brasilia para Brasil. Dada la bilateralidad de su estudio, y también su federalismo, las avenidas de recaudación de fondos para viajes habían sido un torrente casi inagotable: a nadie le preocupaba demasiado que la comparación fuese, por decirlo en forma suave, un poco volada. (61, las cursivas son nuestras)

Gustavo Ramus citaba a Adorno — amaba la trágica y barroca energía de Teodoro (...) a Deleuze -imprescindible para una teoría de la imagen con un nivel aceptable de complejidad-, a Susan Buck-Morss había empezado a leerla para que su marco teórico no fuese acusado de falologocéntrico, terminó convencido por su lectura de Walter Benjamin (...) También a Gastón Bachelard —un solucionador epistemológico de primera línea, muy aceptado por el ala conservadora del jurado de tesis. (61, las cursivas son nuestras)

De una cita a otra se observa cómo varía el tratamiento, según distintas focalizaciones, del mismo escepticismo epistemológico. La primera pasa del siempre ambiguo estilo indirecto libre a una más que evidente valoración que tiene la forma asertiva y universal — con estrategia de atenuación mediante - de la condena social del cinismo ilustrado, que solo un narrador externo podría realizar. En cambio, en la segunda cita vemos el modo predominante de retiro del narrador de la posición de evaluador y su mimetismo con la interioridad de los personajes cínicos y descreídos. Y de nuevo, lo que parece quedar dialogizado como discurso interior cínico, reaparece en el nivel de la narración, adoptando los ideologemas y el razonamiento típico de la crítica ideológica, como en este otro ejemplo:

En alguna de sus ponencias, o quizás en alguna publicación sociológica con referato que habrá cotizado alto frente al Consejo Nacional de Investigaciones Científicas y Técnicas, una publicación cuya sede haya sido algún paraje del extractivismo latinoamericano, en el mejor de los casos... Marcos Osatinsky había escrito sobre la sociabilidad en Mao. (16, las cursivas son nuestras)

El impulso tipificador, no exento de una clase de reduccionismo sarcástico que es común tanto a los personajes retratados como a la voz extradiegética del narrador, señala la persistencia de 
un modo de abordaje de lo real que encuentra en la observación sociológica su forma habitual de enunciación:

Gustavo Ramus tenía el pelo rubio atado en un rodete y usaba pantalones náuticos de color negro arratonado, comprados en el supermercado Jumbo. Esos pantalones eran la indumentaria oficial de los becarios del Consejo Nacional de Investigaciones Científicas y Técnicas que habían asistido al Colegio Nacional de Buenos Aires. (6o, las cursivas son nuestras)

Diremos que la ironía se revela como segura cuando está asentada en un verosímil discursivo que lleva la marca de la sociología del consumo y repercute sobre el efecto de realidad propiciado por el relato futurista. «Mónica Lafuente paseaba por las plataformas con su camisa blanca ajustada, collar de acrílico, lentes de marco morado. Parecía perdida y al mismo tiempo muy tranquila, como si estuviera en una publicidad de aguas saborizadas» (64). La tendencia constante al desenmascaramiento «quínico» (Sloterdijk) de un tipo de narrador que, si bien se mimetiza con el sociologismo «cínico» del cientista promedio focalizado, aun así, es exterior a la acción, señala la supervivencia de una clase de discurso que pretende cierta universalidad validante, más allá del escepticismo de sus usuarios.

La función desenmascaradora de la novela tiene una predilección clara por la estructura de la antítesis y del oxímoron. El primer caso consiste en tomar un sujeto social con cierta tipología aceptada (los investigadores de la cultura) y atribuirles un epíteto aparentemente incongruente que produce el efecto de la farsa (compran Jeans Levi's). Al modelo del intelectual crítico se le adjunta un tipo de idiosincrasia integrada que niega la pertenencia a la identidad primera, haciendo de ese sujeto y los de su clase individuos desviados. La superación de la contradicción se denuncia como cinismo: ser un doble agente (trabajar como investigador para el Estado y trabajar al servicio de las fuerzas productivas, el marketing). La hipérbole satírica se traduce en la reiteración de una misma estructura antitética hasta cobrar la forma de lo congruente.

El oxímoron, por su parte, es el resultado de una contradicción absoluta, como producto de que uno de los términos posee un sema nuclear que es la negación de un clasema del otro término (Grupo $\mu$ :195). En la novela esto se lleva a cabo mediante la adjunción regular de un término no congruente (profano) a otro (elevado): los sermones sufistas son aprehendidos a través de un sistema de karaoke (Vanoli:89), si lo que se busca es denunciar el cinismo de la secta en la que se crían los hackers. Aquí es donde interviene el sentido común que da sostén al régimen de legibilidad del oxímoron. La unión es risible porque ilumina una antítesis cuya garantía es cultural. El sema nuclear del karaoke (entretenimiento) sería la negación de un clasema del otro término que engloba al sufismo (espiritualidad). La oposición entre espiritualidad y entretenimiento confirma un saber previo. Solo así la sátira cobra sentido y el efecto de censura llega a su término. El buen sentido vigila: informa del desvío. Se censura lo censurable; moral limitadora de la sátira, que la ciencia ficción distópica hace propia para construir un verosímil en apariencia realista. La hipérbole satirizante se produce, en suma, por la conjunción reiterada de lo «culturalmente» contradictorio. Si se nos dice que los guerrilleros predican el panarabismo latinoamericano, por medio de un «sufismo de los enfermos» (90), inspirado en el utopismo ruralista de Thoreau, a la suma de elementos «impropios» se agrega que las estrategias implementadas contradicen el espiritualismo (único clasema común a esos significantes), ya sea por tratarse del sabotaje 
o el secuestro extorsivo, o la recaudación de fondos a través de la comercialización de drogas sintéticas. Un mismo significado migra de una referencia a otra, siempre dentro de la antítesis «utopía»/«antiutopía».

Asimismo, el tipo de antítesis redundante que practica la sátira de la novela es consustancial al ethos enjuiciador de la hipérbole. A la conjunción paradojal de lo ya antitético se lo trenza en una segunda construcción propiamente antitética. En la redundancia semántica de la estructura del oxímoron halla previsibilidad y extrae su fuerza «moral» la ironía: «En su paleta de Google Iris ofrecían textos sagrados y el Walden en pdf» (Vanoli:9o). La negación de la antítesis solo es asumida como no contradictoria en el plano de lo literal del enunciado ideológico. Es importante entender que hay un plano último (extradiegético) en la semántica de esta clase de enunciados, cuyo ethos no hace más que confirmar la «naturalidad» de la contradicción y por ende, su censurabilidad. La asunción de la contradicción como no contradictoria (oxímoron) sería, precisamente, un rasgo de multivalencia textual que es incompatible con la ideología conservadora de la sátira. La sátira participa del régimen de lo legible cuando se sostiene en un sistema de solidaridades (como la que presupone el escándalo lógico de la antítesis en el pastiche irónico) que naturalizan el sentido. La enunciación irónica cuando se encuentra bajo el régimen de lo legible se rige por el principio de no contradicción, y es a causa de esto que se vuelve insuficiente para conjurar el «vértigo estereotípico» (Barthes:81), ya que la crítica de los códigos culturales y los estereotipos solo puede establecerse dentro de los límites de un lenguaje autorizado. El discurso clausurado en un círculo de solidaridades que aseguran la coherencia del todo describe la economía textual de la sátira futurista de Vanoli.

Diremos también que la «degradación de la garantía» verdaderamente funciona como tal cuando el metalenguaje científico se entrega a la lógica de la simulación. Surge de aquellos pasajes en que, reduciéndolo a leitmotiv «literario», el relato futurista de aires conspirativos coopta cierto sentido común sociologizante acerca de la convivencia espuria entre intereses políticos corporativos y otros provenientes del capitalismo transnacional. El CONICET habría desarrollado con patrocinio de la corporación biotecnológica (¿cuándo no?), Monsanto, un poderoso plaguicida, prohibido por la OMS, que Rucci y su socio Lorenzo Miguel se disponen a contrabandear con el objetivo de financiar la campaña a gobernador de un candidato de sus filas. Esta contaminación de códigos de referencia hace posible que en el relato se superpongan significantes del campo científico («empresariado», «burocratización ilimitada» —Vanoli:78) que suponen un saber crítico (serio) de la realidad, junto a otros de la cultura de masas, que tienen el valor exclusivo de clichés ("fertilizante superpoderoso» -79-) y ponen en evidencia la mediación total de lo real por un imaginario novelesco que altera definitivamente la confiabilidad de la cognición científica. La utopía, en el marco de pérdida histórica de legitimidad del saber, también cobra el relieve risible, propio de las esperanzas sosas del folletín. El tópico melodramático del giro abrupto en la linealidad cotidiana se presenta como un corte en el verosímil realista de la novela que anuncia la disolución del tipo de racionalidad científica aun restante en la disposición analítica de la voz narrativa. «Ninguno sospechaba, ni de manera remota, que el curso de ese cuasi tramite turístico cambiaria sus vidas para siempre» (22). El pesimismo gnoseológico del tono general de la novela se revierte en un optimismo imaginario, propio del código fetichizado de la aventura, sin bases empíricas.

El acceso a lo real del capitalismo postindustrial se ve impedido por una suma de mediaciones que provienen tanto de imaginarios catastrofistas (acordes a la serie anticognoscitiva 
y pasatista de la $\mathrm{CF}$ ), como del género conspirativo de los documentales políticos a lo Michael Moore, pero también del fenómeno de las tecnologías de búsqueda por internet, y su consecuente sobreinformación, que es otro factor que se revela como estructurante de la neurosis de desenmascaramiento propio de esa elite progresista, integrada en las condiciones de vida semiocapitalistas." Google desplaza a la Escuela de Frankfurt, en tanto fuente y mediador autorizado del conocimiento social:

Marcos Osatinsky había leído que los efectos de la construcción de la represa de Corpus Christi habían sido desastrosos en términos biológicos y climáticos. Buscó en su visor y empezó a leer. Tras tres proyectos diferentes para locaciones tentativas, la represa de Corpus Christi había sido erigida en Pindoí, Misiones, y había contado con una potencia instalada de $3800 \mathrm{MW}$, utilizada al máximo antes de su cese de actividades por sabotajes terroristas. (77, las cursivas son nuestras)

La ironía, no obstante, pareciera sobreponerse a la impotencia del pastiche genérico. Los estilemas de la conspiración y la «literatura mala» (novela de espías, melodrama, gore, etc.) siempre vigilados por un saber de la simulación parecerían quedar, finalmente, subordinados al sistema de la sátira. Lo que se presenta, entonces, como desvío de una genericidad conservadora y autosuficiente es circunstancial y la ciencia ficción queda plenamente asumida en su estructura cognoscitiva.

Tras dos días de convivencia forzosa en un camping cercano a la convención, Clarisa le había regalado a Agustín un desodorante Axe. Al ver el tubo de desodorante elegido por Clarisa, Agustín había empezado a echarse el aerosol directamente sobre su musculosa transpirada, tal como había visto en las publicidades. En ese momento Clarisa había entendido que ese nene tonto que la seguía a todos lados sin entender nada de lo que ella decía, ese hijo de mamá (...) con un leve retardo que lo mantenía atrasado en la escuela, era en realidad un diamante en bruto. (87, las cursivas son nuestras)

La estilización paródica de la escena es total. La anagnorisis de Clarisa no puede ser sino irónica: la sugestión de lo velado define más la personalidad manipuladora de esta suerte de villana de comic, con la inteligencia calculadora de los ejecutivos del marketing que ven «diamantes en bruto» donde encuentran un material humano (targets) posible de modelar a su antojo, que alguna supuesta «realidad social» oculta en la naturaleza del idiotizado por la sociedad de consumo. La verdad que se revela irónicamente no es otra que la de la dominación que a través del sistema de signos del consumo se apropia de las necesidades, convirtiendo al sujeto en consumidor voluntario. Los comportamientos codificados publicitariamente, que, como buena semióloga, Clarisa lee en Agustín, señalan la supervivencia de una cognición científica que, si bien queda trenzada con el código del melodrama, no termina de anular sus efectos por completo.

El relato de la iniciación en el terrorismo new age de Surubí por parte de Agustín se vale, a su vez, de una serie de significantes fungibles de campos sociales inconexos que son la «base» de la doctrina de la guerrilla y, mediante el pastiche desautorizador, son revelados como simulacro guiado solo por una racionalidad de dominio. La inorganicidad programática de la ideología de Surubí radica en la manipulación de consignas que no responden a un programa político común, que en la tradición de la sociedad secreta representada por Arlt, evoca codificadamente 
la demagogia autoritaria y, en el imaginario sociológico contemporáneo, una racionalidad de los fines posideológica. El tránsito natural de la alienación en los signos del sistema del consumo hacia nuevos radicalismos posideológicos (que son la nueva ideología), como lo atestigua la trayectoria modélica de Agustín, representado mediante la hipérbole satirizante y una tipificación caricaturesca, nuevamente, señala la persistencia de un saber del funcionamiento social desde el cual es posible percibir tendencias sociales e individuos ejemplares.

\section{Palabras finales sobre Cataratas y la dialéctica entre destitución y reintegración del discurso sabio}

La intriga conspirativa es la forma degradada y «sumergida» del conocimiento social a la que se pliega la intelligentsia contemporánea, de igual modo que la militancia por Mao es la parodia de la violencia política de los años 70, rasgo identificador común de ese mismo estrato, que atestigua la omnipresencia de la simulación. Puede no haber una teorización explícita acerca de las causas de estos comportamientos, pero hay un lenguaje que evoca ese saber y están los síntomas de esta nueva condición social, que extrapolada al futuro cobra aún más la forma de una lógica subyacente. El saber de la simulación y la semiotización del capitalismo actual es el gran código de referencia que refracta la totalidad de los semas de la novela, dándole unidad a la mixtura aparente de los signos. La lógica de sentido de la sociología del consumo y el discurso de la simulación como ontología del presente se apoderan del plural del texto y, mediante la modulación que le presta el ethos satírico, le sustraen a la función conjetural de la ficción científica posmoderna su resto de multivalencia.

La solución que Cataratas le da a la lógica cognoscitiva del marco genérico depende, en síntesis, de la impronta de la intencionalidad irónica. Si en lo esencial la ciencia ficción es narrativa de conjetura, como afirma Eco, es porque — por excelencia— traduce a juego narrativo el juego científico. ${ }^{2}$ Pero basar la anticipación en un régimen de enunciación que, por acción reiterada de la ironía, termina dando por seguro aquello sobre lo que se conjetura, define un tipo de garantía que clausura el carácter provisorio de la especulación científica y, por ende, limita también el del juego narrativo. Como todo texto legible, la sátira utópica se vale de un tipo de multivocidad restringida: entregada a la Ley del Significado asegura un número limitado de connotaciones (Barthes). Su doble sentido está cuidadosamente elaborado a partir de un código con un fuerte anclaje científico, lo que no impide que muchos de sus semas sean de orden doxológico.

Como consecuencia de la presencia recurrente de índices de la burocratización que afectan a la actividad científica, síntomas de la reificación generalizada, el novum de la ciencia ficción se verosimiliza. Dado que no resulta extraño que los personajes vivan en un simulacro publicitario, también se vuelve plausible que el consumismo exacerbado lleve a naturalizar la presencia anómala —solo en principio — de todo tipo de alteraciones genéticas (transgénesis) con fines culinarios. Si el narrador no se ve en la necesidad de abundar en explicaciones técnicas que justifiquen la existencia futura de la debitación ocular, de visores de tecnología cyborg o de mutaciones de especies, que representan algún tipo de peligro social y desde nuestros cánones parecen aberrantes, es porque construye una lógica en la cual participan conjuntamente cada una de esas novedades que responde a una misma racionalidad instrumental, y que ya estaría "probada» científicamente, aspecto no menos apuntalado por la masividad de los significados usuales del código genérico. Es la nueva doxa de las ciencias sociales y su saber sobre las sociedades 
de control y su alianza con la espectacularización y licuación conjunta de lo real en la fase corporativa del capitalismo actual la que opera como garantía de realidad de la distopía sociológica de Vanoli. Una suma de elementos «futuribles», extraídos no solo del reservorio genérico de la ficción de anticipación sino del imaginario no menos estereotipado de la crítica ideológica, son los que constituyen el fundamento «realista» de la novela.

Sin embargo, por momentos, la novela parecería ejercer un tipo de ironía «no segura» que consiste en la mimetización de la voz narrativa con el cliché, en la oscilación entre un código hermenéutico crítico y otro acrítico, como lo demuestra este pasaje:

Con el tiempo, Clarisa y Agustín habían ahorrado en dólares gracias a lo que juntaban vendiendo esos modestos espectáculos de intimidad. Desde su silla de ruedas, Clarisa administraba todo porque ambicionaba iniciar su propio emprendimiento turístico en la zona. Cada centavo de dólar iba a parar a una cuenta común localizada en las islas Caimán. Solo una vez se habían tomado vacaciones juntos: habían volado a playa del Carmen en un superjet. (92, las cursivas son nuestras)

El narrador al principio gana en neutralidad, volviéndose un frío traductor de las telenovelescas peripecias de la hacker que busca la cura de la enfermedad de su novio-mutante, producida por el gobierno norteamericano como agente de «limpieza poblacional» (82), al código de la investigación social. A esta tendencia podríamos llamarla pulsión epistemológica de la ficción de anticipación, que recurrentemente busca afirmarse como contrapartida de la degradación de la cognición científica que experimenta por sumersión «ideológica» en códigos estereotipados de cultura de masas. Y no obstante, es el mismo discurso «neutral» el que queda «neutralizado» al quedar «inmerso» en la cadena metonímica de un verosímil atestado de lugares comunes subliterarios, que está en las antípodas del conocimiento. Es en estos pasajes, en los que la enunciación se desorigina y pierde fidelidad a un metalenguaje tutor, que se ve más claro el modo en que el pastiche parecería asumir el lugar hegemónico de la sátira. El texto se convierte en el espacio de una fuga de códigos que van contaminándose unos a otros y desrealizando la acción por efecto de una clase de discordancia semántica que mina la autoridad científica. La escritura de Vanoli presenta síntomas de disolución de un metalenguaje autorizado en aquellos momentos en que los juegos de los códigos parecen multiplicarse, impregnando a la ironía de incertidumbre. El saber de lo social parecería así quedar capturado en la misma lógica de la simulación que se denuncia, extrapolada al dispositivo narrativo. Sin embargo, no es esta la función dominante del texto.

La cualidad que representa la distopía de Cataratas de unificar distintos elementos rectores de un presente, extrapolables a un futuro sincrético y esencial - la estructura del paralelismo que acentúa la identidad de los componentes - es una continuidad de la novela de tesis antiutópica tradicional. El deseo de sumisión al concepto es el gran denominador común de la legibilidad clásica, que comparte la ciencia ficción con esta serie de la distopía posgenérica contemporánea. En este sentido, creemos que la palabra de la ciencia ficción es todavía una palabra «clásica» (Barthes), a distancia de la materia que narra (adelantada a esta). Si es capaz de tomar perspectiva, y adelantarse a su tiempo de manera admonitoria, lo hace valiéndose de un «discurso sabio» (Foucault, 1968) que oficie todavía como «criterio de constatabilidad» (Martínez, 2018:88). El carácter cerrado y circular de la economía del sentido que presenta la legalidad científica de la nueva novela de anticipación demuestra que en su inconsciente genérico persiste la tendencia a 


\begin{abstract}
dar como soporte de la ficción un discurso exterior. ¿Es posible que un código supere a otro, manteniendo una relación contrastiva que no detenga el plural del texto, sin declararse «inteligente»? se preguntaba - palabras más, palabras menos- Barthes (173) en alusión al conservadurismo de la parodia. La ciencia ficción ya se ha expedido al respecto. Por más que su hibridez aumente con el tiempo, y el pastiche parezca diseminarla de manera definitiva, la desujeción de su garantía parece ser otro deseo utópico no consumado.
\end{abstract}

\section{Notas}

1 En adelante CF.

2 Tanto Darko Suvin como Luis Cano postulan que la constitución de universos narrativos alternativos acordes a la proyección futurista es la consecuencia de la extrapolación de tendencias predominantes del presente extratextual. El tipo de conexión causal, de carácter admonitorio entre el tiempo de referencia y el futuro proyectado a partir de aquel, es denominada «lógica» por ambos autores dado que se guiaría por parámetros históricos y sociológicos consistentes y verificables. Cfr. Cano:255 y Suvin:43, 64 y 68.

3 Nos referimos fundamentalmente a las ficciones de anticipación escritas en los últimos años por Hernán Vanoli, Pola Oloixarac y Bob Chow. El caso de Félix Bruzzone se adapta mejor a la perspectiva de De Rosso, debido a un tipo de tratamiento del novum genérico que lleva a cabo la novela, que podríamos denominar pseudocientífico. Esta hipótesis será desarrollada en un artículo próximo.

4 Kurlat Ares (2012) observa que la duda acerca de la pertenencia de determinados textos escritos en América Latina a la ciencia ficción se explicaría a partir del desplazamiento de los intereses de la tendencia cientificista o hard por otros de carácter esencialmente sociológico, rasgo predominante de nuestra tradición. Como precisa Luis C. Cano, si bien las categorías hard SF y soft SF son insuficientes para dar cuenta de las particularidades históricas y escriturales de las producciones de ficción científica tanto de Hispanoamérica como del resto del mundo, existiría en las primeras una inclinación general a la incorporación de variantes de las ciencias humanas, en detrimento de las ciencias naturales como sucede en la variante norteamericana (17). Si tuviéramos que arriesgar una hipótesis acerca de un posible linaje hispanoamericano en el que entronque el distopismo de Vanoli, optaríamos por la obra narrativa de Angélica Gorodischer. Comparte con esta no solo el desplazamiento de las hard sciences como sustrato científico de las narraciones, en favor de otras áreas de investigación como la antropología y la sociología, sino, fundamentalmente, la inclinación autorreflexiva y parodizante de la tradición de CF (Cano:229).

5 Se ha preferido el empleo de la noción de distopía a la de antiutopía, teniendo en cuenta la tarea de disociación de una y otra que ha realizado Kumar y que críticos como Moylan retoman y ratifican. Consideramos menos afín a la novela Cataratas la crítica al pensamiento utópico en sí (antiutopía), que la exploración de la hipertrofia generalizada de las tendencias negativas del mundo social en un futuro cercano (o distopía).

6 La relación entre realismo y ciencia ficción queda señalada también por Link, en alusión a la supuesta novedad que con la irrupción del género habría representado la garantía científica, en tanto función de un tipo de validación epistemológica ajena a las leyes internas de la obra literaria. El realismo sería el antecedente más directo de la ficción científica, por presentar la propiedad común de un tipo de legalidad extra-estética impuesta sobre los contenidos representados (9). Más cercano en el tiempo, es Luis C. Cano quien destaca la opción de la CF por una escritura predominantemente lineal, en contraste con el experimentalismo de las convenciones desarrolladas por los escritores del High Modernism. La elección formal de la linealidad, sostenida en un «riguroso desarrollo causal» (214), la describe, en sus comienzos, como versión extrapolada de los parámetros estéticos de la literatura realista. Según el mismo autor, si hay un elemento que explica la actitud de superioridad de la CF con respecto a la literatura fantástica y la asemeja al realismo, es la autoexculpación común del estigma de la ficcionalidad, gracias a la incorporación del discurso científico como elemento autorizante de la ficción.

7 En lo referido a esto, cabe hacer mención a las particularidades de la tradición de escritura del género rioplatense, que difieren sustancialmente de las reconocidas por los críticos tradicionales que mencionamos. El abandono paulatino del 
cientificismo por parte de la ciencia ficción hegemónica, a partir de los años 50 con el auge de la New Wave, como suele señalarse, coincidiría con ciertas características esenciales a la variante fantástica del género que desde los comienzos se habría cultivado en nuestro territorio, como la escasa presencia del elemento tecnológico y el cruce de la cognición científica dominante con paradigmas no legitimados en el campo del conocimiento. La tradición protogenérica nacional, tal como la denomina Martínez (2010), no se ha nutrido de manera exclusiva de paradigmas científicos hegemónicos; al contrario, su episteme se ha caracterizado históricamente por la heterodoxia. La CF hispanoamericana se destacaría por la tendencia a la integración de «la ciencia canónica con otras vías de conocimiento de carácter esotérico» (Cano:21). Llegado este punto, es importante aclarar que la poética de ciencia ficción de Hernán Vanoli que ocupará nuestro análisis poco tiene que ver con la vertiente fantástica o metafísica del género, a nivel regional. En la estela de lo especulativo, sus inquietudes son eminentemente sociológicas. En este sentido, el cientificismo de obras como Cataratas es «clásico». Puede ser paródica, por momentos, pero, de ningún modo, la cognición de la sátira distópica se sostiene en la hibridez de epistemologías alternativas. La prueba más fehaciente de esto es que la «mística» es objeto del desenmascaramiento «quínico» (Sloterdijk) según el código satirizante de la novela. Parece bastante ajeno el texto — en suma- al universo de discusiones de los años 80 en Argentina acerca de la dinámica posible de evolución en la que incluir a la ciencia ficción especulativa rioplatense, contraria al estancamiento de la tradición estadounidense. La disolución de lo «real» sí es un tema relevante en la novela, pero como reflexión acerca de los hipotéticos efectos de la ubicuidad de la racionalidad instrumental en el futuro cercano de Argentina. El «surrealismo» de la novela no coincide, por lo tanto, con el tipo de exploración onírica característica de la «epistemología literaria» de un escritor como Mario Levrero (Martínez, 2019:97). La inmediatez simplificadora del cliché y el «surrealismo» del universo de aventuras codificadas son procedimientos privilegiados del relato, siempre que se los perciba de manera adecuada, como subordinados a un nivel distinto de cognición que los estiliza históricamente, en tanto indicio común de la ontología del capitalismo tardío. Lo que, sin duda, comparte la estética de Cataratas —común también a la colección de relatos, Pyongyang — con la tradición nacional de ciencia ficción es la metaliterariedad. Uno de los materiales fundamentales de la pulsión gnoseológica de la novela, además del instrumental teórico de la ciencias sociales, son los «mitos del género» (Capanna, 1985). En conclusión, heterodoxo — diremos - es el código narrativo, como se intentará demostrar en las próximas páginas, y no así la concepción de lo real, ni el paradigma en el cual se asienta el tipo de especulación literaria que conforma Cataratas.

8 En estudios pioneros como el de Capanna (1966), al referirse a las utopías negativas y el tipo de predicción aciaga que estas realizan, se reiteran de manera enfática los procesos verbales «protestar», «atacar», «criticar», «rechazar» (76-78), signos de un ethos genérico percibido como marcadamente evaluativo. En un libro más reciente como el de Moylan, se observa el mismo uso insistente de ese tipo de subjetivemas, lo que señala, a grandes rasgos, la persistencia de un punto de vista crítico afín en lo que concierne a la preponderancia de la función satírica de la CF. Kinsgley Amis habría sido el primero en señalar que la función esencial de la CF sería la crítica de las costumbres; de allí su visión de esta como sátira social (cfr. Capanna, 1966:8). Tanto Hillegas como más adelante, Suvin o Kumar examinan el origen de los principios formales de la distopía y la antiutopía también en relación directa con la tradición satírica. El texto contemporáneo como el de Cano, por su parte, presenta el problema de atribuirle a la actitud crítica de la CF distópica hispanoamericana las características de lo paródico, cuando su descripción coincide, en buena medida, con el tipo de cuestionamiento ejemplar de la sátira.

9 La hipótesis del idealismo como elemento constitutivo del componente satírico de la ciencia ficción es compartida por Adorno, aunque este le otorga un sentido político decididamente regresivo. Sostiene que del efecto de confrontar por medio de la analogía los rasgos sociales del presente, haciendo que se prolonguen ridículamente en el futuro, provendría el fundamento identitario e idealista de la sátira, base de toda utopía y también de su opuesto.

10 Este argumento se complementa con el esbozado por Chiani en referencia a lo que entiende como la subordinación de la «imaginación científica» (2018:2) y la focalización en los problemas sociales de un hipotético futuro próximo característicos de la ficción anticipadora de Marcelo Cohen, acorde con la impronta renovadora de la New Wave. La subordinación y el desplazamiento de la imaginación científica de la ciencia ficción clásica se darían 
en el marco de un tipo de fantasía distópica en clave de «crítica al neoliberalismo y la globalización» hegemónicas en el tiempo de su escritura (3). Si bien Chiani sitúa la narrativa de Cohen en el contexto de un fuerte relativismo epistémico por participar de un uso intersticial e indirecto de los saberes teóricos, conducidos a la incompletud, es paradójico el valor que en paralelo le otorga a la cognición científica como soporte teórico de la ficción. La hibridez compositiva — vigente desde sus primeras novelasy la «inseguridad» de los fundamentos representativos de su realismo fantástico se explicarían a partir de la presencia de la aleatoriedad expuesta por la teoría del caos, que oficiaría, por lo tanto, de sostén discursivo (Chiani, 1996). Al mismo tiempo, la crítica a la ubicuidad de la dimensión massmediática del orden social confirmaría un linaje común con las teorizaciones de la Escuela de Frankfurt. Ambos sustratos discursivos darían testimonio del apego de la ficción de anticipación de Cohen a un tipo de legibilidad científico-sociológica que por ser ecléctica no debe confundirse con una sensibilidad paródica.
11 La imaginación cyberpunk de la que participa Cataratas atestigua la presencia ubicua de la abstracción, propia del mundo digital. La novela es una exploración de las variantes diversas de la mutación digital que experimenta la percepción al interior de lo que Berardi ha denominado la infoesfera que habitamos en el estadio actual del capitalismo. La proliferación semiótica a la que nos expone la tecnoesfera conectiva aceleraría la percepción del tiempo y la desterritorialización del núcleo de la identidad, empobreciendo la experiencia. Este parecería ser el síndrome del becario de investigación social, cuyo escepticismo cínico resultaría de percibir la pérdida de eficacia simbólica de la sociología y sus saberes críticos, por verse sumidos en el caos de la información.

12 «El procedimiento empleado por la ciencia al predecir los hechos de acuerdo con leyes es el mismo de la anticipación o de la utopía», afirma Capanna (1966:103), refiriéndose a los condicionales contrafácticos, la clase de presuposiciones que, según este, fundan toda la CF.

\section{Referencias}

Adorno, Th. (1955). Aldous Huxley y la utopía. Prismas. La crítica de la cultura y la sociedad. Barcelona: Ariel, 1962, 99-126.

Amis, K. (1960). New Maps of Hell. Nueva York: Hartcourt, Brace.

Barthes, R. (1980). S/Z. Barcelona: Siglo XXI.

Berardi, F. (2018). Fenomenología del fin: sensibilidad y mutación conectiva. Buenos Aires: Caja Negra.

Bruzzone, F. (2014). Las chanchas. Buenos Aires: Literatura Random House.

Butor, M. (1964). La crise de croissance de la science-fiction. Essais sur les Modernes. Paris: Les Editions des Minuits, 223-237.

Cano, L. (2006). Intermitente recurrencia: la ciencia ficción y el canon literario hispanoamericano. Buenos Aires: Corregidor.

Capanna, P. (1966). El sentido de la ciencia ficción. Buenos Aires: Columba.

Capanna, P. (1985). La ciencia ficción y los argentinos. Minotauro, (10), 43-56.

Capanna, P. (2007). Ciencia ficción: utopía y mercado. Buenos Aires: Cántaro.

Chiani, M. (1996). Escenas de la vida postindustrial: sobre El Fin de lo mismo de Marcelo Cohen. Orbis Tertius, 1(1), 117-130.

Chiani, M. (2018). Ficción paranoica, violencia y memoria (s) en la narrativa de Marcelo Cohen. Revista Alter/ nativas, 8. https://alternativas.osu.edu/es/issues/spring-8-2018/essays5/chiani.html

Cohen, M. (1999). La ciencia ficción y las ruinas de un porvenir. Punto de Vista, 65, 17-23.

De Rosso, E. (2012). La línea de sombra: literatura latinoamericana y ciencia ficción en tres novelas contemporáneas. Revista Iberoamericana, LXXVIII(238/239), 311-328.

Donawerth, J. (2003). Genre blending and the critical dystopia. En Moylan, T. y Baccolini, R. (Eds.). Dark Horizons: science fiction and the dystopian imagination. London: Routledge, 2016, 26-46. 
Chow, B. (2016). Todos contra todos y cada uno contra sí mismo. Buenos Aires: La bestia equilátera.

Eco, U (1988). Los mundos de la ciencia ficción. De los espejos y otros ensayos. Barcelona: Lumen, 183-190.

Foucault, M. (1968). La proto-fábula. En Bellour, R.; Foucault, M. y otros. Verne: un revolucionario subterráneo. Buenos Aires: Paidós, 37-47.

Freedman, C. (2000). Critical theory and science fiction. Hanover, NH: Wesleyan University Press.

Frye, N. (1965). Varieties of literary utopías. Daedalus, 94(2), 323-347.

Grupo $\mu$. (1987). Retórica general. Barcelona: Paidós.

Hillegas, M. (1967). The future as nightmare: H. G. Wells and the Anti-Utopians. New York: Oxford University Press.

Horne, L. (2011). Literaturas reales: transformaciones del realismo en la narrativa latinoamericana contemporánea. Buenos Aires: Beatriz Viterbo.

Hutcheon, L. (1981). Ironie, satire, parodie: une aproche pragmatique de l'ironie. Poétique, (46), 467-477.

Kumar, K. (1988). Utopia and Anti-utopia in modern times. Oxford: Basil Blackwell.

Kurlat Ares, S. (2012). La ciencia ficción en América Latina: entre la mitología experimental y lo que vendrá. Revista Iberoamericana, LXXVIII(238/239), 15-22.

Kurlat Ares, S. (2017). La ciencia ficción en América Latina. Aproximaciones teóricas al imaginario de la experimentación cultural». Revista Iberoamericana, LXXXIII(259/260), 255-261.

Link, D. (1994). Prólogo. En Daniel Link (Ed.). Escalera al cielo. Utopía y ciencia ficción. Buenos Aires: La Marca, $5^{-15}$.

Ludmer, J. (2010). Aquí América latina. Una especulación. Buenos Aires: Eterna Cadencia.

Lundwall S. (1986). Aventuras en la jungla de pulpa. El Péndulo, (13), 67-78. Traducción de Gardini, C.

Martínez, L. (2010). Políticas de traducción y publicación de las revistas de ciencia ficción argentinas (1979-1987). Sendebar. Revista de la Facultad de Traducción e Interpretación, (21), 109-138.

Martínez, L. (2018). Imaginarios de la ciencia. El Taco en la Brea, (7), 86-91.

Martínez, L. (2019). La doble rendija: Autofiguraciones científicas de la literatura en el Río de la Plata. Buenos Aires: Prometeo.

Moylan, Th. (2000). New maps of hell. Scraps of the untainted sky. Science fiction, utopia, dystopia. Boulder: Westview Press, 111-145.

Oloixarac, P. (2015). Las constelaciones oscuras. Buenos Aires: Random House.

Rabkin, E. (1976). The fantastic in literature. Princeton, New Jersey: Princeton University Press.

Sloterdijk, P. (2003). Crítica de la razón cínica. Madrid: Siruela.

Suvin, D. (1979). Metamorfosis de la ciencia ficción. Sobre la poética y la historia de un género literario. México: Fondo de Cultura Económica, 1984.

Todorov, T. (1980). Introducción a la literatura fantástica. México: Premia.

Vanoli, H. (2015). Cataratas. Buenos Aires: Literatura Random House. 